\title{
Audit Sistem Informasi untuk Meningkatkan Kapabilitas Proses Pada Sistem Informasi Akademik di Perguruan Tinggi menggunakan Cobit 4.1 Berdasarkan ISO/IEC 15504
}

\author{
(Studi Kasus STKIP Garut)
}

\author{
Dian Nurdiana, Andri Suryadi \\ Program Studi Pendidikan Teknologi Informasi, Institut Pendidikan Indonesia Garut \\ dian.nurdiana060211@yahoo.com, andrisuryadi@institutpendidikan.ac.id
}

\begin{abstract}
Abstrak. Sistem informasi akademik merupakan sebuah sistem yang berfungsi untuk membantu layanan akademik, sistem akademik yang baik tentunya bisa memberikan pelayanan yang maksimal terhadap mahasiswanya. STKIP Garut merupakan salah satu perguruan tinggi yang sudah menggunakan sistem informasi akademik, namun terdapat beberapa permasalahannya seperti data tidak akurat dan perangkat lunak yang masih banyak bug. Oleh karena itu butuh sebuah model yang bisa meningkatkan kapabilitas IT sehingga bisa meningkatkan kinerja dari sistem informasi akademik. Model pengukuran COBIT 4.1 menggunakan metode Process Assessment Model merupakan salah satu model yang digunakan untuk meningkatkan kapabilitas proses IT, model ini mendukung penilaian kapabilitas kinerja tata kelola teknologi informasi dengan menyediakan indikator sebagai pedoman dalam interpretasi tujuan proses dan keluaran yang didefinisikan dalam COBIT 4.1 dan atribut proses yang didefinisikan dalam ISO/IEC 15504 dengan pengukuran kapabilitas didasarkan pada sembilan atribut proses, kesembilan atribut di atas terdapat dalam level-level kapabilitas proses dan harus dipenuhi untuk mencapai suatu level. Dari hasil penelitian ini didapatkan tingkat pencapaian kapabilitas proses pada sistem informasi akademik di STKIP Garut, kemudian memberikan rekomendasi untuk bisa menyelesaikan permasalahan yang sedang dihadapi dan rekomendasi untuk meningkatkan level kapabilitas proses berdasarkan COBIT 4.1 menggunakan metode Process Assessment Model.
\end{abstract}

Kata Kunci: Sistem informasi akademik, Cobit 4.1, Assessment Model, Kapabiltias Proses.

\begin{abstract}
Information System Audit to Improve The Process Capability on Academic Information System of College Using COBIT 4.1 Based on ISO/IEC 15504 (Case Study of STKIP Garut)). Academic information system is a system function to help academic service, in which a good academic system gives maximum service to the students. STKIP Garut is one of the colleges that has already applied academic information system, but there are still problems of inaccurate data and bug in the software. Therefore, a model which can improve the IT capability is needed to increase the performance of academic information system. COBIT 4.1 measurement model uses method of Process Assessment Model which is utilized to improve IT Process capability. It supports the performance capability assessment of information technology management by providing indicator as a guide for output and objective process interpretation defined in COBIT 4.1. It is also a process attribute defined in ISO/IEC 15504 with the capability measurement based on nine process attributes existed in levels of process capabilities and need to be fulfilled to reach a level. The research resulted in obtaining level of process capability achievement in academic information system in STKIP Garut and giving a recommendation to solve the existing problems and improving level of process capability based on COBIT 4.1 using method of Process Assessment Model.
\end{abstract}

Keywords: Academic Information System, Cobit 4.1, Assessment Model, Process Capability.

\section{Pendahuluan}

Sistem informasi merupakan salah satu sumber utama dari organisasi yang harus dikelola dengan baik seperti sumber daya lainnya. Karena, dengan pengelolaan dan memelihara sistem informasi akan memberikan keuntungan kompetitif terhadap keberlangsungan proses bisnis dari organisasi. Salah 
satu keuntungan kompetitif dari memelihara sistem informasi yaitu dapat meningkatkan arus informasi antara perusahaan maupun elemen lingkungannya sehingga diharapkan bisa meningkatkan pencapaian tujuan organisasi (Hartanto, Indra Dwi \& Tjahyanto, Aries).

Namun di era globalisasi saat ini pengelolaan terhadap sistem informasi tidaklah mudah, hal ini dikarenakan oleh pergeseran atau perubahan dari permintaan konsumen dan kompetitif ekonomi yang berubah dengan cepat mengakibatkan proses bisnis perusahaan harus bisa mengimbangi perubahaan tersebut. Sehingga sistem informasi juga harus bisa merespon dan membantu dalam pendukung keputusan dengan cepat agar mampu mencapai tujuan organisasi dengan cepat juga.

Sistem informasi akademik adalah salah satu perkembangan dalam mengelola informasi. Dengan dikembangkan sistem informasi akademik bertujuan membantu dalam mengelola data-data akdemik yang ada di perguruan tinggi. Sehingga diharapkan dengan adanya sistem informasi akademik dapat membatu layanan akademik yang lebih baik apalagi Kenyataan menunjukkan bahwa saat ini teknologi jaringan interkoneksi komputer (Internet) tidak dapat dipisahkan dalam berbagai masalah yang dihadapi oleh berjuta orang di dunia (Harahap, 2004).

STKIP Garut merupakan salah satu perguruan tinggi yang sudah mengembangkan dan menerapkan sistem informasi akademik untuk membantu proses layanan akademik kepada mahasiswanya. Sistem informasi akademik ini di kelola dan dikembangkan oleh divisi yang khusus mengelola sistem informasi dan komputerisasi dilingkungan STKIP Garut. Menurut divisi yang mengelola sistem informasi di STKIP Garut, sistem informasi akademik yang saat ini benar-benar dibutuhkan oleh lembaga saat ini, oleh karena itu pada saat ini mereka sedang focus dalam mengembangkan sistem informasi akademik agar bisa membantu dengan maksimal terhadap layanan akdemiki untuk mahasiswanya. Namun dalam pengembanganya terdapat beberapa masalah yang sering dihadapi seperti tidak akuratnya data dan masih ada masalah diperangkat lunak yang disebabkan oleh kesalahan kode program pada aplikasi yang mana hal ini akan berpengaruh terhadap layanan akademik terhadap mahasiswanya (Suryadi, 2017).

Dari permasalan diatas maka perlu pengelolaan yang mampu menyelesaikan permasalahanpermasalah yang terjadi saat ini. Dengan menyelesaikan permasalah-permasalah tersebut diharapkan bisa meningkatkan kualitas maupun kinerja dari sistem informasi akademik di STKIP Garut. Cobit 4.1 Process Assesment Model merupakan salah satu model yang berisi kerangka dasar dari proses pengelolaan IT. Model ini memberikan penilaian sejauh mana pencapaian kapabilitas proses yang telah dilakukan oleh STKIP Garut dalam mengimplementasikan sistem informasi akdemiknya. Setelah mengetahui posisi pencapaian kapabilitas proses, kemudian kita bisa merekomendasikan bagaimana cara menyelesaikan permasalahan dan menaikan level kapabilitas proses dari sistem informasi akademik. Karean semakin baik level kapabilitas proses yang dicapai maka kinerja dan pengelolaan dari sistem informasi akademik di STKIP Garut akan lebih baik.

Berdasarkan latar belakang diatas maka penulis bermaksud membuat penelitian yang berjudul "Audit Sistem Informasi Untuk Meningkatkan Kapabilitas Proses Pada Sistem Informasi Akademik di Perguruan Tinggi Menggunakan Cobit 4.1 Berdasarkan ISO/IEC 15504 (Studi kasus STKIP Garut)".

\section{Metode Penelitian}

\subsection{Tahapan Penelitian}

Tahapan penelitian ditunjukkan pada desain penelitian sebagaimana ditampilkan pada gambar 1, dimana tahapan penelitian diawali dengan perumusan masalah dan tujuan penelitian, serta diakhiri dengan rekomendasi dan kesimpulan. 


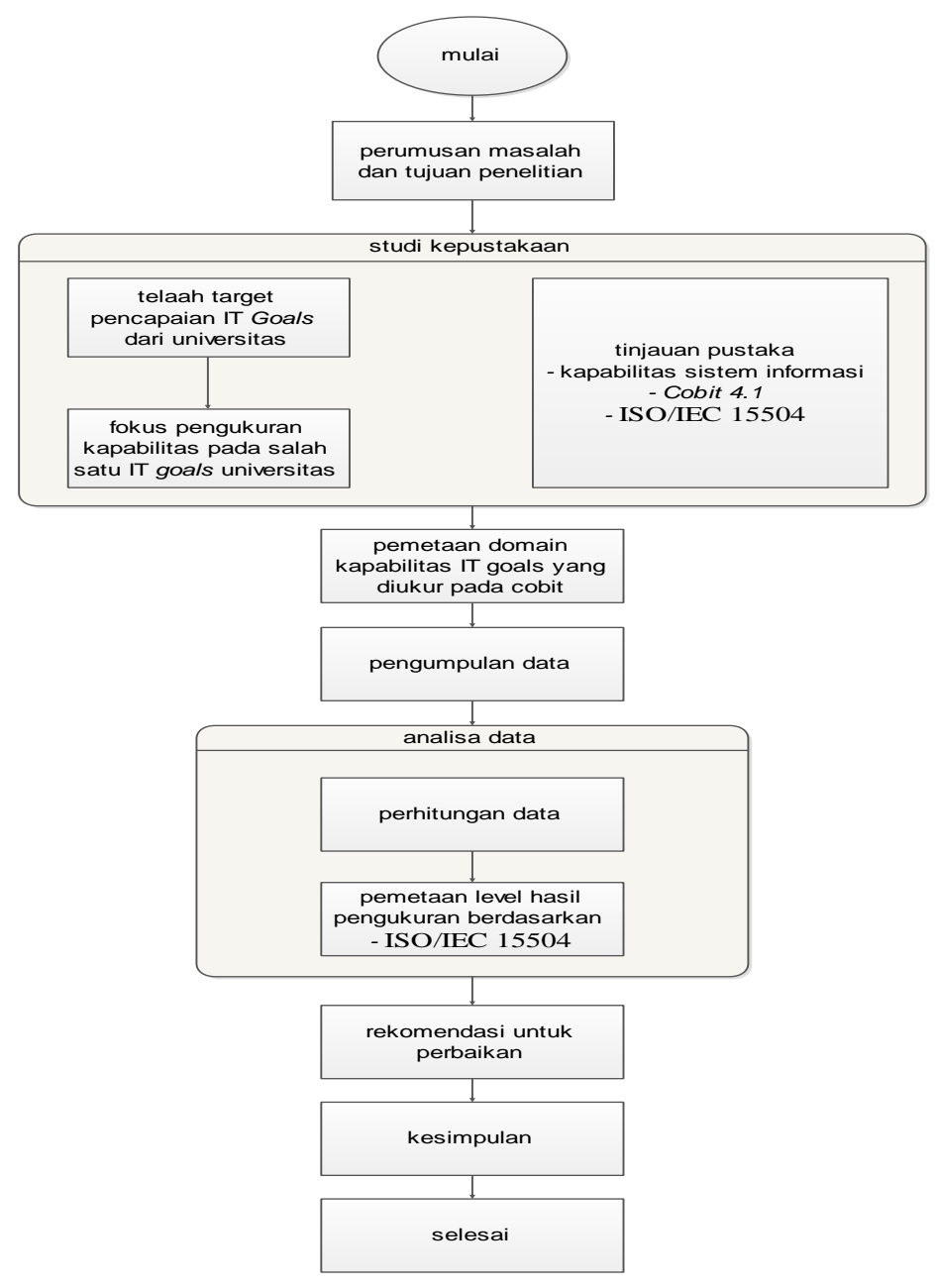

Gambar 2.1. Desain Penelitian

\subsection{Perumusan Masalah dan Tujuan Penelitian}

Pada bagian pertama penelitian ini akan membahas sekilas mengenai perumusan masalah dan tujuan dari penelitian ini. Rumusan masalah memuat uraian yang menyebutkan secara spesifik maksud atau tujuan yang hendak dicapai dari penelitian yang dilakukan. Maksud-maksud yang terkandung didalam kegiatan tersebut baik maksud utama maupun tambahan harus dikemukakan dengan jelas.

\subsection{Studi Kepustakaan}

Studi kepustakaan diharapkan mampu menggali seluruh informasi yang terkait dengan permasalahan yang akan diteliti dan objek yang menjadi tujuan penelitian. Studi kepustakaan ini memberikan dasar bagi arah penelitian yang akan dilakukan serta menjadi awal pemikiran bagi setiap peneliti sehingga penelitian yang dilakukan dapat dijadikan acuan kembali dikemudian hari.

\section{Tinjauan Pustaka}

Tinjauan pustaka merupakan pencarian dasar-dasar teori yang mendukung dengan penelitian. Tinjauan pustaka ini bisa berupa paper dari penelitian sebelumnya ataupun teori-teori yang berkaitan dengan permasalahan penelitian seperti audit sistem informasi, framework tata kelola sistem informasi dan teori pendukung lainnya yang digali oleh penulis. Studi literatur dilakukan dengan membaca, merangkum, kemudian menuliskannya kembali dengan metode yang telah ditentukan. Penelitian ini 
memfokuskan diri pada model tingkat kapabilitas proses dari universitas dengan menggunakan Cobit 4.1 berdasar pada ISO 15504 yang merupakan standar dari dimensi kapabilitas (Marina,2012).

\subsection{Telaah Target Pencapaian Universitas}

Proses ini dilakukan untuk meninjau target pencapaian IT dari universitas. Peninjauan bisa dilakukan dengan cara menggali dokumen maupun wawancara dengan bagian IT di universitas. Dari proses ini diharapkan bisa mengetahui potensi terutama dalam mengelola sistem informasi. Dari target pencapaian IT universitas nantinya akan dipetakan dengan IT goal pada Cobit 4.1 yang akan lebih jelas di bahas pada tahap selanjutnya.

\subsection{Fokus Penelitian Pada Salah Satu IT Goal Organisasi}

Selanjutnya setelah mengetahui target pencapaiannya kemudian untuk memfokuskan dalam analisis maka perlu difokuskan target pencapaian mana yang akan diukur. Tujuan dari memfokuskan target pencapaian IT ini dimaksudkan agar bisa mengetahui kapabilitas apa yang nantinya akan diukur menggunakan Cobit 4.1 berdasarkan ISO 15504. Selain itu apabila tidak difokuskan maka cakupan proses IT nya akan sangat luas, sehingga bila proses IT tersebut difungsikan semuanya maka dibutuhkan pengerjaan yang lama.

\subsection{Pemetaan Domain}

Pemilihan domain COBIT didapatkan dengan menyelaraskan tujuan bisnis dengan tujuan IT. Pemetaan domain Cobit 4.1 berawal dari visi-misi organisasi, kemudian visi-misi tersebut dipetakan kedalam 4 perspektif antara lain: Financial (Corporate) Perspective, Customer Perspective, Internal Perspective, Learning and Growth Perspective. Setiap perspektif memiliki beberapa business goals yang berkaitan dengan perspektifnya. Kemudian setiap business goals juga memiliki beberapa IT goals. Sama dengan business goals, IT goals juga memiliki beberapa process yang dimasukkan kedalam 4 kategori domain. Pemetaan dilakukan langsung dari IT goal STKIP kepada IT goal Cobit 4.1.

\subsection{Pengumpulan Data}

Untuk mengumpulkan data pada penelitian ini penulis menggunakan dua cara. Pertama, dengan cara mengadakan wawancara terpimpin yang dilakukan dengan membawa sederetan pertanyaan lengkap dan terperinci seperti yang dimaksudkan dalam wawancara terstruktur (Nuraini, 2015).

\section{Analisis Data}

\subsection{Perhitungan Data}

Setelah dilakukan pengumpulan data, selanjutnya data-data tersebut diolah dengan metode statistik pengolahan kuesioner. Dari hasil perhitungan akan didapatkan nilai berupa persentasi ketercapaian dari proses kapabilitas. Pada penelitian ini terdapat lima opsi jawaban yaitu; jawaban 1 sampai dengan 5. Dengan kriteria sebagai berikut :

Tabel 3.1 Kriteria

\begin{tabular}{|c|l|}
\hline No & \multicolumn{1}{|c|}{ Kriteria } \\
\hline 1 & Sangat kurang \\
\hline 2 & Kurang \\
\hline 3 & Cukup \\
\hline 4 & Baik \\
\hline 5 & Sangat baik \\
\hline
\end{tabular}




\subsection{Pemetaan Level Hasil Pengukuran Berdasarkan ISO 15504}

Metode COBIT 4.1 Process Assessment Model mendukung penilaian kapabilitas kinerja tata kelola teknologi informasi dengan menyediakan indikator sebagai pedoman dalam interpretasi tujuan proses dan keluaran yang didefinisikan dalam COBIT 4.1 dan atribut proses yang didefinisikan dalam ISO/IEC 15504. Pengukuran kapabilitas didasarkan pada sembilan atribut proses. Kesembilan atribut di atas terdapat dalam level-level kapabilitas proses dan harus dipenuhi untuk mencapai suatu level.

- Level 0 - Incomplete process

- Level 1 - Performed process

- Level 2 - Managed process

- Level 3 - Established process

- Level 4 - Predictable process

- Level 5 - Optimizing process

Dalam melakukan pengukuran, setiap atribut pada tiap level juga harus diberikan rating dengan skala sebagai berikut:

Tabel 3.2 Skala Pencapaian Kapabilitas

\begin{tabular}{|c|c|}
\hline Skala & Pencapaian \\
\hline $0 \%-15 \%$ & Not Achieved \\
\hline $15 \%-50 \%$ & Partially Achieved \\
\hline $50 \%-85 \%$ & Largely Achieved \\
\hline $85 \%-100 \%$ & Fully Achieved \\
\hline
\end{tabular}

Sebuah proses dapat dinyatakan mencapai tingkatan kapabilitas tertentu apabila seluruh atribut yang ada pada tingkat tersebut memiliki rating "Fully Achieved" atau "Largely Achieved", dengan seluruh atribut pada tingkat dibawahnya memiliki rating "Fully Achieved".

\subsection{Rekomendasi Untuk Perbaikan}

Untuk permasalah yang dihadapi organisasi, rekomendasi yang diberikan akan berdasarkan kontrol apa saya yang belum tercapai sesuai dengan Cobit 4.1. Ketercapaian kontrol tersebut dapat dilihat dari hasil analisa kesenjangan yang dilakukan sebelumnya. Pada tahapan akhir ini penulis menyimpulkan hasil penelitian yang diperoleh. Kesimpulan yang diperoleh memuat bagaimana kondisi tata kelola sistem informasi untuk proses pengelolaan sistem informasi akademik pada organisasi saat ini, kondisi tata kelola sistem informasi yang diharapkan sebagai acuan perbaikan dan strategi perbaikan bagi manjemen untuk mencapai kondisi yang diharapkan tersebut. (Amrul, 2010).

\section{Hasil dan Pembahasan}

\subsection{Pengukuran Kapabilitas Menggunakan PAM}

Dalam rangka melakukan penelitian mengenai kemampuan IT, maka penelitian dilakukan melalui beberapa tahap instrumen penelitian. Perkembangan yang cepat dari instrumen penelitian yang semakin handal dan valid dapat meminimalkan kesalahan pada pengukuran. Pengukuran kapabilitas pada penelitian ini akan berfokus pada pengelolaan sistem akademik. Metode pengukuran pada penelitian ini akan menggunakan metode pengukuran Cobit 4.1 berdasarkan ISO/IEC 15504 . Level kapabilitas akan dibagi menjadi 5 level seperti pada tabel 4.1: 
Tabel 4.1 Tingkat Kapabilitas pada ISO/IEC 15504

\begin{tabular}{|c|l|}
\hline Level Kapabilitas & \multicolumn{1}{c|}{ Attribute } \\
\hline 5 - Optimizing & PA.5.1 Process Innovation \\
& PA 5.2 Process Optimization \\
\hline 4 - Predictable & PA.4.1 Process Measurement \\
& PA 4.2 Process Control \\
\hline \multirow{2}{*}{3 - Established } & PA.3.1 Process Definition \\
& PA 3.2 Process Deployment \\
\hline \multirow{2}{*}{2 - Managed } & PA.2.1 Performance Management \\
\hline \multirow{2}{*}{1 - Performed } & PA2.2 Work Product Management \\
\hline & PA.1.1 Process Performance \\
\hline
\end{tabular}

Penilaian model proses didefinisikan dalam dokumen ini sesuai dengan ISO / IEC 15504-2 persyaratan untuk model proses penilaian, dan dapat digunakan sebagai dasar untuk melakukan penilaian terhadap kemampuan setiap proses COBIT 4.1. Dalam melakukan pengukuran, setiap atribut pada tiap level juga harus diberikan rating dengan skala sebagai berikut [ISACA, 2011]:

Tabel 4.2 Skala Pencapaian Kapabilitas

\begin{tabular}{|c|c|}
\hline Skala & Pencapaian \\
\hline $0 \%-15 \%$ & Not Achieved \\
\hline $15 \%-50 \%$ & Partially Achieved \\
\hline $50 \%-85 \%$ & Largely Achieved \\
\hline $85 \%-100 \%$ & Fully Achieved \\
\hline
\end{tabular}

Sebuah proses dapat dinyatakan mencapai tingkatan kapabilitas tertentu apabila seluruh atribut yang ada pada tingkat tersebut memiliki rating "Fully Achieved" atau "Largely Achieved", dengan seluruh atribut pada tingkat dibawahnya memiliki rating "Fully Achieved" [Ducan, 2002]. Untuk lebih jelasnya mengenai metode penelitian ini bisa dilihat pada gambar 3.1. Pada gambar tersebut menggambarkan tahapan yang dilakukan dalam penelitian, mulai dari awal sampai akhir dari penelitian yang bertujuan memberikan kesimpulan dan saran dari penelitian.

\subsection{Pemetaan antara IT Goal STKIP GARUT dan IT Goal Cobit 4.1}

Dalam era modern sekarang ini, informasi menjadi suatu komoditi yang sangat penting. Penguasaan informasi beserta teknologinya menjadi kunci keberhasilan dalam persaingan global saat ini. STKIP GARUT sebagai sebuah Institusi yang mempunyai komitmen untuk mengikuti perkembangan teknologi informasi sudah seharusnya memiliki sebuah team (divisi) yang handal dibidang tersebut, maka dengan alasan itulah STKIP GARUT Center didirikan.

Untuk memfokuskan penelitian ini, maka target pencapaian atau IT Goal STKIP GARUT yang akan diukur dalam penelitian ini adalah sistem informasi akademik STKIP GARUT. Tabel 4.5 menunjukkan pemetaan dari target pencapaian atau IT Goal STKIP GARUT dengan IT Goal pada Cobit 4.1. hasil pemetaan tersebut bertujuan untuk memilih domain mana yang sesuai dengan target pencapaian IT organisasi. 
Tabel 4.5 Pemetaan Antara IT Goal STKIP GARUT dan IT Goal Cobit 4.1

\begin{tabular}{|c|l|c|c|}
\hline No & \multicolumn{1}{|c|}{ IT Goals STKIP GARUT } & No & IT Goal Cobit 4.1 \\
\hline 4 & $\begin{array}{l}\text { Memastikan bahwa perguruan tinggi memiliki sistem } \\
\text { informasi yang dimanfaatkan untuk komunikasi } \\
\text { internal dan eksternal kampus serta akses bagi } \\
\text { mahasiswa dan dosen terhadap sumber-sumber } \\
\text { informasi ilmiah. Ada bukti bahwa sistem informasi } \\
\text { yang dikembangkan telah dimanfaatkan untuk } \\
\text { komunikasi internal dan eksternal kampus serta akses } \\
\text { bagi mahasiswa dan dosen terhadap sumber-sumber } \\
\text { informasi ilmiah }\end{array}$ & 11 & $\begin{array}{l}\text { Memastikan aplikasi } \\
\text { terintegrasi ke dalam } \\
\text { proses bisnis. }\end{array}$ \\
\hline
\end{tabular}

Setelah melakukan pemetaan antara IT goal STKIP GARUT dan IT goal Cobit 4.1 diperoleh IT Goal nomor 11 pada Cobit 4.1. Selanjutnya adalah menghubungkan antara IT goal dengan proses yang sesuai berdasarkan Cobit 4.1. Tabel 4.6 dibawah ini menunjukkan nomor proses yang sesuai dengan IT goal Cobit 4.1.

Tabel 4.6 Pemetaan IT Goal Dengan Proses

\begin{tabular}{|c|c|c|}
\hline No & IT Goals Cobit 4.1 & \multicolumn{1}{c|}{ Proses } \\
\hline 6 & Memastikan aplikasi terintegrasi ke dalam proses bisnis. & AI1, AI2, dan AI6. \\
\hline
\end{tabular}

Dari hasil menghubungkan atau pemetaan IT goal dengan proses didapatkan nomor proses yang sesuai yaitu AI1, AI2, dan AI6. Tabel 4.7 menjelaskan keterangan dari nomor proses yang dihasilkan dari pemetaan.

Tabel 4.7 Keterangan Proses Pada Cobit 4.1

\begin{tabular}{|c|l|}
\hline No & \multicolumn{1}{|c|}{ Keterangan Proses Pada Cobit 4.1 } \\
\hline AII & $\begin{array}{l}\text { Identify automated solutions: Memenuhi kebutuhan bisnis untuk mengidentifikasi } \\
\text { solusi otomatis yang menerjemahkan persyaratan fungsional dan kontrol bisnis } \\
\text { menjadi solusi yang efektif dan efisien }\end{array}$ \\
\hline AI2 & $\begin{array}{l}\text { Acquire and maintain application software: Memenuhi kebutuhan bisnis dengan } \\
\text { menyelaraskan aplikasi yang tersedia dengan persyaratan keamanan bisnis pada waktu } \\
\text { yang tepat dan dengan biaya yang wajar. }\end{array}$ \\
\hline AI6 & $\begin{array}{l}\text { Manage changes: Memenuhi kebutuhan bisnis dengan mengelola perubahan TI } \\
\text { dengan strategi bisnis untuk mencari solusi dan mengurangi kerusakan pada pelayanan. }\end{array}$ \\
\hline
\end{tabular}

\subsection{Analisis Hasil Pengumpulan Data}

Pada COBIT 4.1 Process Assessment Model, ketercapaian suatu level diukur berdasarkan ketercapaian atribut yang ada pada level tersebut dan level sebelumnya. Berdasarkan aturan pada ISO/IEC 15504, ketercapaian level 2 dapat diukur apabila level 1 telah terpenuhi dan atribut pada level 1 telah mencapai rating "Fully Achieved". Ketercapaian level 3 dapat diukur bila level 2 terpenuhi dan semua atribut pada level 2 telah mencapai rating "Fully Achieved". Hal ini berlaku pula untuk level-level selanjutnya. Namun, pada penelitian ini, akan dilakukan pengukuran untuk semua level pada kapabilitas proses sehingga seluruh kuesioner akan diberikan untuk pengumpulan data. Hal ini 
untuk mengetahui ketercapaian seluruh level pada pengelolaan sistem informasi akademik di STKIP GARUT.

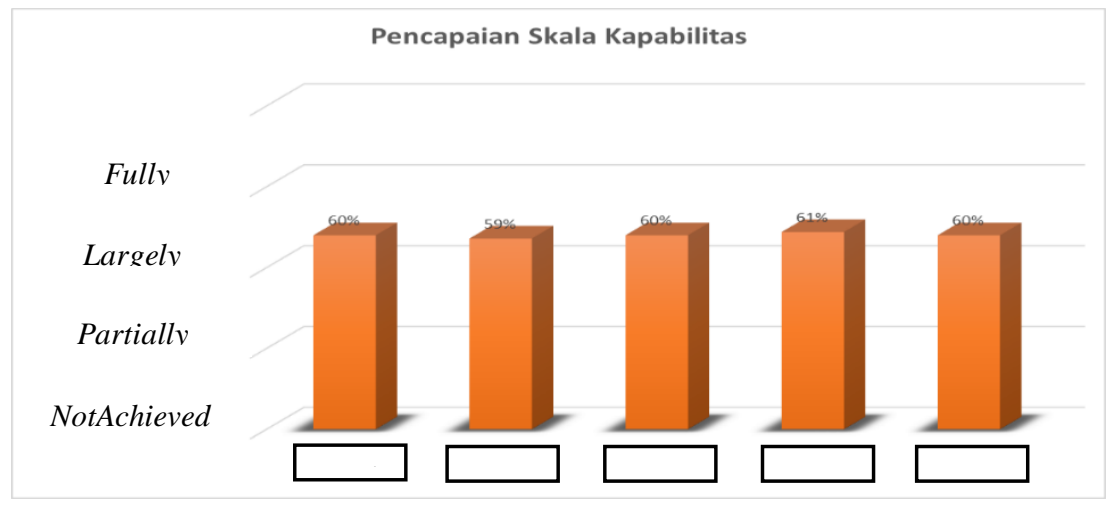

Gambar 4.1 Pencapaian Skala Kapabilitas

Dari hasil pengukuran yang dilakukan untuk level 1 sampai dengan level 5 pada dengan menggunakan COBIT 4.1 Process Assessment Model. Level 1 memiliki ketercapaian sebesar 60\% yang berarti skala ketercapaian diposisi Largely Achieved, Level 2 memiliki ketercapaian sebesar 59\% yang berarti skala ketercapaian diposisi Largely Achieved, Level 3 memiliki ketercapaian sebesar $60 \%$ yang berarti skala ketercapaian diposisi Largely Achieved, Level 4 memiliki ketercapaian sebesar $61 \%$ yang berarti skala ketercapaian diposisi Largely Achieved, Level 5 memiliki ketercapaian sebesar $60 \%$ yang berarti skala ketercapaian diposisi Largely Achieved.

Berdasarkan standar yang ada dalam COBIT 4.1 Process Assessment Model, tata kelola sistem informasi akademik di STKIP GARUT telah mencapai tingkat kapabilitas level 1. Karena pada sebuah proses dapat dinyatakan mencapai tingkatan kapabilitas tertentu apabila seluruh atribut yang ada pada tingkat tersebut memiliki rating "Fully Achieved" atau "Largely Achieved", dengan seluruh atribut pada tingkat dibawahnya memiliki rating "Fully Achieved" [Ducan, 2002].

\section{Kesimpulan}

Dari hasil pengukuran pada sistem informasi akademik di STKIP GARUT yang dilakukan untuk level 1 sampai dengan level 5 pada dengan menggunakan COBIT 4.1 Process Assessment. Level 1 memiliki ketercapaian sebesar 60\% yang berarti skala ketercapaian diposisi Largely Achieved, Level 2 memiliki ketercapaian sebesar 59\% yang berarti skala ketercapaian diposisi Largely Achieved, Level 3 memiliki ketercapaian sebesar 60\% yang berarti skala ketercapaian diposisi Largely Achieved, Level 4 memiliki ketercapaian sebesar $61 \%$ yang berarti skala ketercapaian diposisi Largely Achieved, Level 5 memiliki ketercapaian sebesar 60\% yang berarti skala ketercapaian diposisi Largely Achieved.

Berdasarkan standar yang ada dalam COBIT 4.1 Process Assessment Model, tata kelola sistem informasi akademik di STKIP GARUT telah mencapai tingkat kapabilitas level 1. Karena pada sebuah proses dapat dinyatakan mencapai tingkatan kapabilitas tertentu apabila seluruh atribut yang ada pada tingkat tersebut memiliki rating "Fully Achieved" atau "Largely Achieved", dengan seluruh atribut pada tingkat dibawahnya memiliki rating "Fully Achieved" [Ducan, 2002].

Rekomendasi yang akan diberikan dibuat kedalam dua tahan. Tahap pertama didalamnya memberikan rekomendasi perbaikan untuk permasalahan yang sedang terjadi, sedangkan rekomendasi perbaikan untuk tahap kedua dibuat untuk meningkatkan level kapabilitas proses dari sistem informasi akademik. Peningkatan level ini bertujuan untuk memperbaiki kapabilitas proses lainnya, dengan adanya peningkatan kapabilitas proses diharapkan kinerja sistem informasi akademik akan lebih baik dan permasalahan yang kemungkinan muncul dimasa yang akan datang akan tertanggulangi dari sekarang. 
Tujuan dari peningkatan proses kapabilitas IT adalah meningkatkan kemampuan IT dalam mendukung proses bisnis. Pada penelitian ini proses bisnis yang dimaksud adalah pelayanan sistem pendukung keputusan. Ketika level kapabilitas proses IT lebih baik maka kemampuan IT dalam mendukung pelayanan sistem informasi akademik akan lebih baik sehingga kinerja dari akan lebih maksimal (Schreyögg, 2007).

\section{Referensi}

[1] Amrul, Sadat S \& Hardi, Enny. Pengaruh Organizational Learning Dan It Capability Terhadap Financial Performance. JAAI Volume 14 NO. 1, Juni 2010: 87-99

[2] Harahap, E. Strategi Perencanaan Instalasi Jaringan Internet Menggunakan Metode Analytic Hierarchy Process, Jurnal Matematika UNISBA, Vol. 3, No. 1, Mei 2004.

[3] Hartanto, Indra Dwi \& Tjahyanto, Aries. Analisa Kesenjangan Tata Kelola Teknologi Informasi Untuk Proses Pengelolaan Data Menggunakan Cobit (Studi Kasus Badan Pemeriksa Keuangan Republik Indonesia)". Surabaya: Teknologi Sepuluh Nopember. 2012.

[4] ISACA, COBIT®. Assessment Process (CAP): COBIT® 4.1 Process Assessment Model, IL. USA: ISACA, 2011.

[5] Marina, Ade Putri \& Kridanto, Surendro. Perancangan Model Kapabilitas Proses Pengelolaan Sumber Daya Teknologi Informasi". Vol. 1, No. 2, Juli 2012. Jurnal Sarjana Institut Teknologi Bandung Bidang Teknik Elektro dan Informatika.

[6] Nuraini, J., Fajar, M.Y., Harahap, E. Pemilihan Biodiesel Terbaik Berdasarkan Penggabungan Analytic Hierarchy Process (AHP) dan Technique for Order preference by Similarity to Ideal Solution (TOPSIS). Jurnal Matematika UNISBA, Vol. 16, No. 1, Mei 2017.

[7] Schreyögg, G \& Kliesch-Eberl, M. How dynamic can organizational capabilities be? Towards a dualprocess model of capability dynamization. Strategic Management Journal, vol. 28, no. 9, 2007. pp. 913.

[8] Suryadi, A., Harahap, E. Pemeringkatan Pegawai Berprestasi Menggunakan Metode AHP (Analytic Hierarchy Process) di PT. XYZ. Jurnal Matematika UNISBA. Vol. 16, No. 2, Desember 2017. pp. 17-28.

[9] S. P. Duncan. Making Sense of ISO 15504 (And SPICE). 2002. 